\title{
GEOQUÍMICA E A PROVENIÊNCIA DE ROCHAS METASSEDIMENTARES DETRÍTICAS ARQUEANAS DOS GREENSTONE BELTS DE CRIXÁS E GUARINOS, GOIÁS
}

\author{
H.Jost ${ }^{1}$, A.M.G.Figueiredo ${ }^{2}$
}

\begin{abstract}
Sedimentos podem ser um meio natural de amostragem da crosta exposta (Goldschmidt, 1933). Estudos recentes mostram que rochas sedimentares ricas em argilominerais do Arqueano contrastam geoquimicamente com as do Proterozóico e Fanerozóico (Taylor \& McLennan, 1985). Os primeiros estudos da natureza geoquímica e ensaios de proveniência de rochas metassedimentares detríticas arqueanas de Goiás são recentes (Jost et al., 1995). Este discute a natureza geoquímica de rochas metassedimentares detríticas das porções estratigráficas superiores dos greenstone belts $(2.8 \mathrm{Ga})$ contíguos de Crixás e Guarinos, Goiás. As rochas estudadas consistem de espessos filitos carbonosos sobrepostos a metabasaltos toleiíticos e sotopostos a metaturbiditos distais (metarenitos, metasiltitos e metargilitos).

As proporções de óxidos de elementos maiores e menores e elementos traços dos três litotipos são similares. A variação de $\mathrm{SiO}_{2}, \mathrm{TiO}_{2}, \mathrm{Al}_{2} \mathrm{O}_{3}, \mathrm{Fe}_{2} \mathrm{O}_{3}{ }^{*}$ e $\mathrm{Na}_{2} \mathrm{O}$ de filitos carbonosos e metargilitos é menor que, mas está contida na dos metarenitos. A variação de $\mathrm{MgO}$, $\mathrm{CaO}, \mathrm{MnO}$ e $\mathrm{K}_{2} \mathrm{O}$ dos metargilitos e metarenitos é menor, mas está contida na dos filitos carbonosos. Nos três litotipos, $\mathrm{K}_{2} \mathrm{O}$ cresce e $\mathrm{MgO}, \mathrm{Fe}_{2} \mathrm{O}_{3 \mathrm{Tot}}$ e $\mathrm{CaO}$ decrescem com $\mathrm{SiO}_{2}$, em resposta às proporções de sericita e clorita.
\end{abstract}

Cerca de $85 \%$ das amostras possuem uma razão CIA = $\mathrm{SiO}_{2} /\left(\mathrm{Al}_{2} \mathrm{O}_{3}+\mathrm{CaO}+\mathrm{Na}_{2} \mathrm{O}+\mathrm{K}_{2} \mathrm{O}\right)$ entre 0.7 e 0.9 , sugerindo uma intensidade de intemperismo na área-fonte insuficiente para gerar caolinita, mas suficiente para illita, montmorilonita ou beidelita e pode, portanto, ser considerado como moderado. Outros $10 \%$ possuem CIA entre 0.7 e 0.4 , semelhante ao dos modernos depósitos glaciais argilosos e implicando em intemperismo químico baixo. Apenas $5 \%$ das amostras possuem CIA $>0.9$ e podem denotar intemperismo extremo ou mesmo reciclagem sedimentar.

A abundância média dos óxidos de elementos maiores e menores e de elementos em traço (ETR, U, Th, Sc, $\mathrm{Co}, \mathrm{Ni}, \mathrm{Cr}, \mathrm{Ba}, \mathrm{Zr}, \mathrm{Hf}, \mathrm{Th}$ ) mostra que as proporções de $\mathrm{Al}_{2} \mathrm{O}_{3}, \mathrm{SiO}_{2}$, ETRP, U, Y e $\mathrm{Sr}$ das rochas estudadas são similares à média das suas equivalentes pós-arqueanas (NASC). Contudo, enquanto as primeiras são mais ricas em $\mathrm{Fe}_{2} \mathrm{O}_{3 \text { tot }}, \mathrm{CaO}, \mathrm{MgO}$, $\mathrm{MnO}, \mathrm{Ba}, \mathrm{V}, \mathrm{Cr}, \mathrm{Ni}$, Co e Sc que as últimas, estas são mais ricas em $\mathrm{K}_{2} \mathrm{O}, \mathrm{Na}_{2} \mathrm{O}, \mathrm{TiO}_{2}, \mathrm{P}_{2} \mathrm{O}_{5}, \mathrm{Zr}$ e ETRL. Isto sugere que o modelo de composição média granodiorítica das áreas continentais pós-arqueanas, refletida no NASC, não se aplica às rochas metassedimentares estudadas, as quais requerem uma área-fonte máfica, como também indicam suas proporções de $\mathrm{Cr}$ (100 a $2000 \mathrm{ppm}$, média $=600 \mathrm{ppm})$ e Ni $(20$ a $1000 \mathrm{ppm}$, média $=600$ e $200 \mathrm{ppm})$.

0 EETR varia de 25 e $295 \mathrm{ppm}$. Cerca de $50 \%$ das amostras contêm entre 20 e $100 \mathrm{ppm}$, compativel com as proporções comumente observadas em rochas metassedimentares

\footnotetext{
${ }^{1}$ Instituto de Geociências, Universidade de Brasilia.

${ }^{2}$ Instituto de Pesquisas Energéticas e Nucleares/Conselho Nacional de Energia Nuclear, São Paulo.
} 
detriticas do Arqueano e grauvacas pobres em quartzo do Fanerozóico. Cerca de $40 \%$ possui entre 100 e $200 \mathrm{ppm}$ e $10 \%$ entre 200 e $300 \mathrm{ppm}$, teores típicos de grauvacas ricas a intermediárias em quartzo do Fanerozóico. O intervalo de 200 a 300 ppm contém as concentrações anômalas, normalmente situadas em metarenitos.

Os ETR normalizados ao NASC mostram que filitos carbonosos, metasiltitos e metarenitos possuem assinaturas similares e todos ocorrem em duas populações que se distinguem pela abundância de ETRL. Comparativamente aos equivalentes pós-arqueanos, as rochas estudadas são mais pobres em ETRL, possuem anomalias positivas de $\mathrm{Eu}_{\mathrm{N}} / \mathrm{Eu}^{*}{ }_{\mathrm{N}}$ e ausência de fracionamento das ETRP. Isto indica uma área-fonte com pouca influência de uma componente félsica, em beneficio da participação de plagioclásio e minerais ferromagnesianos.

Em diagrama Th-La-Sc, as amostras distribuem-se segundo um arranjo linear a partir do Sc em direção ao $\mathrm{La}$, em contraste com sedimentos pós-arqueanos e indicando que a carga detrítica dos protolitos das rochas estudadas resultaram de proveniências máficas e félsicas. $\mathrm{O}$ modelamento de proveniência empregando $\mathrm{Cr} / \mathrm{Ti}$ versus $\mathrm{Zr} / \mathrm{Y}$ permite concluir que a composição destas se explica pela mistura de detritos sólidos provenientes de uma área fonte dominantemente máfica, eventualmente ultramáfica, subordinadamente félsica arqueanas (PAS). Conclui-se, também, que a transição de ambiente anóxico, reinante logo após o término do vulcanismo basáltico, para ambiente turbidítico distal não implicou em mudança nas características composicionais da área fonte.

\section{Referências Bibliográficas}

GOLDSCHMIDT, V.M. (1933) Petrographie und geochemie; grundlagen der quantitativen geochemie. Fortschritte der Mineralogie, Kristallographie und petrographie, v.17, p.112-156.

TAYLOR, S.R.; McCLEANNAN, S.M. (1985) The continental crust: its composition and evolution. Oxford, Blackwell. 312p.

JOST, H.; FIGUEIREDO, A.M.G.; FERREIRA, A.V. (1995) Elementos em traço e a proveniência clástica na transição de ambiente euxênio para turbidítico em metassedimentos do greenstone belt de Guarinos, Goiás. In: CONGRESSO BRASILEIRO DE GEOQUIMICA, 5./CONGRESSO DE GEOQUÍMICA DOS PAÍSES DE LÍNGUA PORTUGUESA, 3., Niterói, 1995. Anais. Niterói, SBGq. (CD-ROM) 